\title{
Mediação de conflitos na gestão da saúde (médica, clínica e hospitalar): humanização do direito médico
}

Mediation of conflicts in health management (medical, clinical and hospital): humanization of medical law

Mediación de conflictos en la gestión sanitaria (médica, clínica y hospitalaria): humanización del derecho médico

\begin{abstract}
Resumo
Objetivo: demonstrar que o processo de mediação de conflitos se apresenta como resposta adequada na prevenção, gestão e resolução de divergências, onde existam relações continuadas e o interesse em construir soluções efetivas, globais e duradoras. Metodologia: o presente trabalho é baseado em uma revisão bibliográfica e na experiência profissional da autora, por meio das suas intervenções e vivências práticas, com mais de $5.000 \mathrm{~h}$ de experiência só em mediação. Resultados: na sua maioria os conflitos entre as diferentes subculturas na saúde - médica, enfermagem, administrativa, relações com paciente e família, bem como, mais recentemente, a tecnologia de informação e robótica na saúde têm relação direta com distintas formas de trabalho, autoridade e legitimidade, compreendidos como divergentes e maioritariamente entendidos como incompatíveis e inconciliáveis. De igual forma, é indispensável conhecer e incorporar na organização processos de diálogo e negociação consensual, voluntários e confidenciais, como a mediação, facilitados por um terceiro imparcial, sem poder de decisão ou julgamento. Resulta confirmada a necessidade de as lideranças na saúde saberem lidar com a complexidade dos conflitos, que permanecem entre as diferentes subculturas. Organizações e gestores que utilizam processos consensuais de forma técnica potencializam experiências positivas, bem como melhoram indicadores de qualidade no ambiente social organizacional. Conclusão: espera-se que os gestores médicos, clínicos e hospitalares desenvolvam competências de prevenção, gestão e resolução consensual de conflitos, sendo necessário desenvolver e aprofundar o triângulo do conhecimento do processo de mediação.
\end{abstract}

Palavras-chave: Mediação. Competência cultural. Administração de serviços de saúde. Conflito de interesses. Direito à saúde.

\begin{abstract}
Objective: to demonstrate that the conflict mediation process presents itself as an adequate response in the prevention, management and resolution of differences, where there are ongoing relationships and the interest in building effective, global and lasting solutions. Methodology: the present work is based on a bibliographic review and on the author's professional experience, through her interventions and practical experiences, with more than 5,000 hours of experience in mediation alone. Results: most of the conflicts between the different subcultures in health - medical, nursing, administrative, patient and family relations, as well as, more recently, information technology and robotics in health - are directly related
\end{abstract}

\footnotetext{
${ }^{1}$ Mestre em Direito; coordenadora da Pós-graduação LLM em Mediação, Gestão e Resolução de Conflitos na Escola Superior de Advocacia (ESAOAB-MG). E-mail: dulcemnascimento@gmail.com
} 
to different forms of work, authority and legitimacy, understood as divergent and mostly understood as incompatible and irreconcilable. Likewise, it is essential to know and incorporate consensual, voluntary and confidential dialogue and negotiation processes in the organization, such as mediation, facilitated by an impartial third party, with no decision or judgment power. It is confirmed the need for health leaders to know how to deal with the complexity of conflicts, which remain between the different subcultures. Organizations and managers who use consensual processes in a technical way enhance positive experiences, as well as improve quality indicators in the organizational social environment. Conclusion: it is expected that medical, clinical and hospital managers develop competences for the prevention, management and consensual resolution of conflicts, being necessary to develop and deepen the knowledge of the mediation process.

Keywords: Mediation. Cultural competency. Health services administration. Conflict of interest. Health rights and justice.

\section{Resumen}

Objetivo: este artículo tiene como objetivo demostrar que el proceso de mediación de conflictos se presenta como una respuesta adecuada en la prevención, gestión y resolución de diferencias, donde existen relaciones continuas, así como un interés en construir soluciones efectivas, globales y duraderas. Metodología: el presente trabajo se basa en la revisión bibliográfica, así como en la experiencia profesional de la autora, a través de sus intervenciones y experiencias prácticas, con más de 5,000 horas de experiencia solo en mediación. Resultados: los conflictos entre las diferentes subculturas en salud (médica, enfermería, administrativa, en la relación con el paciente y la familia, así como, más recientemente, con la inclusión de la tecnología de la información y la robótica en la salud), la mayoría de ellas tienen una relación directa con diferentes formas: trabajo, autoridad y legitimidad, entendido como divergente, entendido principalmente como incompatible e irreconciliable. Asimismo, es esencial conocer e incorporar procesos de diálogo y negociación consensuales, voluntarios y confidenciales en la organización, como la mediación, facilitados por un tercero imparcial, sin decisión ni juicio. Se confirma que los líderes de salud necesitan saber cómo lidiar con la complejidad de los conflictos, que permanecen entre las diferentes subculturas. Las organizaciones y gerentes que usan procesos consensuados de manera técnica mejoran las experiencias positivas, así como también mejoran los indicadores de calidad en el entorno social organizacional. Conclusión: se espera que los gerentes médicos, clínicos y hospitalarios desarrollen competencias para la prevención, el manejo y la resolución consensuada de conflictos, y es necesario desarrollar y profundizar el triángulo de conocimiento del proceso de mediación.

Palabras clave: Mediación. Competencia Cultural. Administración de los Servicios de Salud. Conflicto de Intereses. Derecho a la salud.

\section{Introdução}

Vivemos num mundo global, que se transformou numa aldeia global, onde tecnologia e inteligência artificial ocupam cada vez mais espaço, substituindo funções humanas em diversas profissões, em especial as relacionadas com tarefas repetitivas, bem como outras que exigem uma maior precisão, oferecendo um menor risco de erro e segurança de resultado, como se verifica, por exemplo, através da robótica na saúde. 
Se, por um lado, mudanças ocorrem numa velocidade cada vez mais vertiginosa, por outro, nem sempre é possível acompanhar, em especial face ao conjunto de tarefas individuais assumidas pelos sujeitos nas sociedades ditas modernas, ao nível pessoal, familiar, profissional e social. Estão surgindo novas realidades e desafios, em especial na área da saúde, provocadas pelo desenvolvimento de sensações de impotência, bem como stress nos indivíduos e relações.

Atendendo ao tema que nos propomos desenvolver, de gestão de conflitos na saúde, importa começarmos por questionar e refletir sobre a realidade, o contexto e mudanças.

Entendemos ser de suma importância recorrer aos objetivos de desenvolvimento sustentável (ODS), definidos pela ONU em 2015 e insertos na Agenda 2030, que devem ser implementados por todos os países para transformar o mundo, a saber:

1. Acabar com a pobreza em todas as suas formas, em todos os lugares

2. Acabar com a fome, alcançar a segurança alimentar e melhoria da nutrição e promover a agricultura sustentável

3. Assegurar uma vida saudável e promover o bem-estar para todos, em todas as idades

4. Assegurar a educação inclusiva e equitativa e de qualidade, e promover oportunidades de aprendizagem ao longo da vida para todos

5. Alcançar a igualdade de gênero e empoderar todas as mulheres e meninas

6. Assegurar a disponibilidade e gestão sustentável da água e saneamento para todos

7. Assegurar o acesso confiável, sustentável, moderno e a preço acessível à energia para todos

8. Promover o crescimento econômico sustentado, inclusivo e sustentável, emprego pleno e produtivo e trabalho decente para todos

9. Construir infraestruturas resilientes, promover a industrialização inclusiva e sustentável e fomentar a inovação

10. Reduzir a desigualdade dentro dos países e entre eles

11. Tornar as cidades e os assentamentos humanos inclusivos, seguros, resilientes e sustentáveis

12. Assegurar padrões de produção e de consumo sustentáveis

13. Tomar medidas urgentes para combater a mudança climática e seus impactos $^{2}$

14. Conservação e uso sustentável dos oceanos, dos mares e dos recursos marinhos para o desenvolvimento sustentável

15. Proteger, recuperar e promover o uso sustentável dos ecossistemas terrestres, gerir de forma sustentável as florestas, combater a desertificação, deter e reverter a degradação da terra e deter a perda de biodiversidade 16. Promover sociedades pacíficas e inclusivas para o desenvolvimento sustentável, proporcionar o acesso à justiça para todos e construir instituições eficazes, responsáveis e inclusivas em todos os níveis

\footnotetext{
${ }^{2}$ Reconhece que a Convenção Quadro das Nações Unidas sobre Mudança do Clima (UNFCCC, sigla em inglès) é o fórum internacional intergovernamental primário para negociar a resposta global à mudança do clima.
} 
17. Fortalecer os meios de implementação e revitalizar a parceria global para o desenvolvimento sustentável

Dos dezessete objetivos definidos pela ONU, entendemos que o ODS no 3 é relevante para o presente trabalho, ao "assegurar uma vida saudável e promover o bem-estar para todos, em todas as idades”, identificando o objetivo como o dever de garantir saúde e bemestar, promovendo a prosperidade. Também consideramos relevante referir e reforçar o $\mathrm{n}^{\circ}$ 16, ao "promover sociedades pacíficas e inclusivas para o desenvolvimento sustentável, proporcionar o acesso à justiça para todos e construir instituições eficazes, responsáveis e inclusivas em todos os níveis", no sentido de melhorar a qualidade de vida dos indivíduos. Dito de outra forma, o ODS 16 tem como objetivo paz, justiça e instituições eficazes.

A escolha dos dois objetivos levou em consideração o entendimento de que eles se encontram intimamente ligados com a humanização do direito médico, por meio da implementação de uma gestão na área da saúde (médica, clínica e hospitalar), com base em princípios colaborativos e de resolução consensual, em especial por meio dos princípios e processo de mediação de conflitos, conforme pretendemos demonstrar durante e ao final do presente trabalho.

Ao falarmos de saúde e bem-estar, assim como da promoção da prosperidade, em especial no mercado da saúde privada, precisamos refletir sobre como o aumento da esperança média de vida está relacionado com a profissionalização e uso da tecnologia, ocorrendo, também, um aumento da lucratividade dessa área, substituindo o padrão antigo de um mercado de saúde maioritariamente assistencialista. Também se impõe entender e aprofundar sistemas que ofereçam mais qualidade com maior eficiência e eficácia, atendendo ao mercado cada vez mais competitivo e utilizadores cada vez mais informados e exigentes.

$\mathrm{Na}$ atualidade, seja na área clínica, médica ou hospitalar, em especial no mercado privado, vivemos em um ambiente competitivo, com contornos empresariais complexos, onde é necessário ter competências de gestão especializada, a qual importa uma visão de mapa do negócio, mas também das especificidades dos conflitos.

No caso específico da gestão na saúde, em particular na área hospitalar, precisamos entender com profundidade a área clínica, mas também as áreas de hotelaria e nutrição. Diferentemente do hóspede que paga por uma noite no hotel e tem data certa para sair, na hotelaria hospitalar o paciente entra, muitas vezes, sem saber quanto tempo vai ficar naquele espaço, que denominamos de quarto, a ser a sua habitação vinte e quatro horas por dia. Com igual relevância, olhemos para a área de nutrição hospitalar: ao invés de ir a um 
restaurante e escolher a refeição do cardápio, o paciente fica refém do serviço de alimentação que lhe é prestado, de acordo com o perfil a que está a ser tratado. Hotelaria e nutrição dizem respeito a conforto, bem-estar e qualidade da hospitalidade que a organização oferece, sendo esses serviços totalmente distintos dos serviços médicos e clínicos que o paciente necessita para receber alta médica e poder sair daquele local.

Impõe-se a tomada de consciência de que as áreas clínica, médica e hospitalar passaram de uma prestação meramente assistencialista para uma atuação de prestador de serviços, passando a oferecer cuidados secundários (cura e tratamento), assim como terciários (reabilitação e reintegração), para além de ensino (hospital escola), pesquisa e investigação biomédica (cura de doenças raras).

Podemos afirmar que hoje temos organizações extraordinariamente complexas, na sua estrutura física, tecnológica e humana, as quais impõem aos seus gestores e administradores uma enorme capacidade de reação assertiva, com modelos eficientes e eficazes à mudança, que o meio e as necessidades dinâmicas do mercado lhes exigem.

As particularidades mencionadas, acrescidas de outras mais técnicas, exigem das novas lideranças hospitalares processos gerenciais para lidar com os conflitos que surgem, a fim de atender a necessidade de ultrapassar o desafio de transição do modelo de gestão tradicional para modelos empresariais destas organizações.

O presente trabalho pretende estimular os gestores da área da saúde, em especial nas especificidades das atuações médica, clínica e hospitalar, a tomarem consciência sobre a importância de desenvolverem competências de prevenção, gestão e resolução consensual de conflitos e, em especial, sobre conflito, comunicação e negociação, com o objetivo de focar na sua área principal de negócio e resolver os conflitos de forma célere e confidencial, preservando a imagem dos intervenientes, sujeitos físicos e organizações.

Além da revisão de bibliografia diversa, a principal fonte deste estudo encontra-se nas intervenções e vivências práticas da autora, tendo por base as mais de 5.000 horas de experiência só em mediação, salvaguardando o princípio da confidencialidade, imposto de forma ética e legal, no Brasil e em Portugal.

\section{Resultados e discussão}

A área da saúde, em especial a organizacional, seja ela médica, clínica ou hospitalar, caracteriza-se por integrar um conjunto de diferentes subculturas, destacando-se a médica, 
da enfermagem, do diagnóstico, laboratorial, técnica especializada, bem como, mais recentemente, a tecnologia de informação, a robótica na saúde, a engenharia e informática. A essas, acrescem a administrativa, financeira, comercial, marketing, entre outras mais executivas e operacionais. Por fim, e não menos importante, além do consumidor final, onde nos deparamos com particularidades culturais do paciente, há a família e amigos, além da sociedade local em geral.

Atendendo às mencionadas particularidades sociais e culturais, podemos afirmar que os conflitos na área da saúde se caracterizam, maioritariamente, por envolverem multipartes, o que por si só impõe uma necessária especialidade técnica para que o profissional que trabalha com essa gestão, antes de tomar uma posição e decidir como proceder, consiga diagnosticar os diferentes elementos, sujeitos, posições, interesses e particularidades da situação tida como divergente, incompatível e conflitante.

A grande maioria das situações que o alto gestor na área da saúde é chamado a resolver têm relação direta com distintas formas de trabalho, autoridade e legitimidade, compreendidas como divergentes, sendo em grande parte entendidas como incompatíveis e inconciliáveis. Dedicar-se à gestão e resolução desse tipo de eventos, caracterizados com elementos relacionais e ligados à execução da operação, além de retirar o foco principal do gestor da otimização dos resultados esperados, ocupa um percentual significativo do seu tempo com desgastes emocionais e relacionais, bem como tendencialmente distrai os gestores do foco de desenvolvimento organizacional e otimização dos resultados.

Consideramos indispensável conhecer e incorporar na gestão da saúde (médica, clínica e hospitalar) processos de diálogo e negociação consensual, voluntários e confidenciais, como a mediação de conflitos, facilitados por um terceiro imparcial ao tema em divergência, sem interesse no resultado nem poder de julgamento ou decisão, cuja atuação potencializará a humanização do direito médico.

Modelos de gestão: vertical (autoritário/ distributivo) e matricial (autonomia/ restaurativo)

Tradicionalmente, há uma tensão, muito frequente e recorrente, entre a realidade médica e a gestão ou administração organizacional, com repercussão nas lideranças e necessária interrelação. Quando encontramos lideranças do corpo de especialistas, (em especial, médicos e enfermeiros, que têm poder de decisão com dimensão administrativa 
no uso de recursos, a sua orientação se faz pela sua formação profissional técnica (urgência e risco) e não pelo modelo de gestão empresarial.

Diferentemente, o corpo gerencial advindo da área de administração, que se encontra distante do cotidiano médico, exerce funções de processos de adesão dos colaboradores e controle dos resultados alcançados. Os processos de gestão e administração ocorrem com inúmeras situações de tensão entre as mencionadas subculturas (subcultura de especialistas técnicos com a subcultura administrativa).

Atendendo às referidas especificidades, os modelos e processos de gestão clínica, médica e hospitalar precisam manter a sua missão para com a saúde e o compromisso para garantir o bem-estar individual e coletivo, promovendo a prosperidade e melhorando a qualidade de vida dos indivíduos. Por outro lado, é necessário racionalizar, por meio da objetividade dos processos de gestão, para alcançar paz e justiça, bem como instituições e organizações eficientes e eficazes.

Atendendo ao exposto, importa referir que existem vários modelos de liderança na gestão, sendo o escolhido determinante para os resultados alcançados. Recorrendo a Maximilian Karl Emil Weber (1), intelectual, jurista e economista alemão, considerado um dos fundadores da Sociologia, esclarece que podemos classificar três comportamentos de liderança: autoritário, liberal e democrático. Segundo Weber (1) a distinção encontra-se centrada na conduta adotada pelo líder. No modelo autoritário o líder fixa diretrizes a serem seguidas, sem qualquer participação do grupo; já o modelo democrático tem ênfase no líder e nos seus subordinados, sendo as diretrizes debatidas e escolhidas pelo grupo com a assistência do líder; por fim, o modelo liberal enfatiza a participação dos subordinados, verificando-se uma liberdade e autonomia dos subordinados, que passam a ser denominados de colaboradores (2), com autonomia para tomarem decisões e assumirem a correspondente responsabilidade pelas escolhas assumidas.

A evolução dos modelos de liderança, em especial do modelo liberal, com estruturas cada vez mais horizontais ou até mesmo de cariz matricial, veio demonstrar que, na prática, existem colaboradores com posições em níveis hierárquicos inferiores com grande capacidade de liderança, por vezes até maior que a do próprio gestor, podendo os modelos consensuais e de colaboração fortalecer a instituição como um todo (3). Sucede que, para esse tipo de modelo dar certo é necessário existir um elevado padrão de confiança entre os 
envolvidos na relação, pois só assim e consegue alcançar a necessária segurança sobre a responsabilidade pelas tomadas de decisão.

Como podemos verificar, para enfrentar os desafios da atualidade, os gestores hospitalares da atualidade precisam ter competências de liderança no campo administrativo, acompanhadas de legitimidade junto às subculturas de especialistas (4).

Organizações caracterizadas por modelos horizontais, e mais recentemente por modelos matriciais, necessitam ter $m$ atenção que gestão e liderança precisam caminhar juntas e em sintonia (5), sendo fundamental saber a sua distinção. De forma sumária, gestão relaciona-se com planejamento a curto prazo, organização, controle e resolução de divergências, enquanto liderança está mais relacionada com desenvolvimento de estratégias, inspiração, bem como motivação de pessoas e grupos (6), produzindo mudanças e transformações.

Conforme Matos (6), as instituições da saúde, face à elevada competitividade, acrescida das exigências do mercado pela prestação de serviços e atendimento de qualidade, assumem cada vez mais contornos empresariais, impondo-se uma profissionalização da sua gestão com especiais competências de liderança.

Quando pensamos em liderança e gestão, em especial na saúde, precisamos ter presente a complexidade das organizações, pois ali encontramos diferentes contextos e distintas relações entre administradores, gestores e colaboradores, coexistindo diferentes subculturas no mesmo espaço organizacional (7).

De forma generalista, podemos concluir pela existência de duas grandes subculturas, que por vezes se chocam em termos de gestão (8), causando conflitos de interesse e que também podem ser conflitos de status, egos ou mera divergência de pontos de vista sobre o mesmo assunto. A subcultura médica realiza atividades em função do que considera tecnicamente correto, defendendo sempre a autonomia e maior a liberdade de atuação, justificando que as situações não podem ser catalogadas e, em consequência, deixa com frequência de seguir protocolos e padrões. Por outro, a subcultura administrativa, por regra sem conhecimento clínico ou médico, com dificuldade de reconhecer a influência histórica que a subcultura médica exerce no cotidiano de um hospital, tentando fazê-la seguir regras orientadas para o processo de profissionalização, em busca de controle de custos, aumento da produtividade e busca pela qualidade, por meio de padronização das operações, sem a participação prévia daqueles na tomada dessas decisões. 
Sucede que, apesar da possibilidade de interesses próprios (que podem ser divergentes entre corpo clínico, enfermagem e administrativo), o bom andamento das atividades da organização, como um todo, depende da efetiva harmonia e relacionamento saudável entre os diferentes atores envolvidos na estrutura organizacional, porquanto apenas juntos será possível ter uma organização em completo e efetivo funcionamento.

É de extrema importância a liderança existente em cada grupo para otimizar a concretização das diretrizes organizacionais por parte dos diferentes colaboradores, gerindo de forma mais eficiente e eficaz conflitos de interesse ou eventuais faltas de alinhamento com as estratégias organizacionais, minimizando situações de disputas de poder ou mesmo de instabilidade entre subculturas que precisam atuar de forma conjunta.

As organizações têm cada vez mais solidificada a ideia de absoluta necessidade de coexistência das subculturas, em especial dentro do complexo mundo organizacional hospitalar, verificando-se de extraordinária importância os gestores e administradores dominarem o triângulo do conhecimento para os métodos consensuais (9), onde incluímos temas como conflito, comunicação assertiva e negociação por interesses, perante diferentes conflitos organizacionais (internos e externos), para a concretização de modelos de governança com elevado padrão de qualidade do serviço prestado e ambiente organizacional (10), bem como na relação com o paciente e família.

\section{Conflito na gestão da saúde}

Partindo dos conceitos sobre a moderna teoria do conflito, abordados em artigo publicado anteriormente, pretendemos agora, com maior profundidade, desenvolver o tema do conflito hospitalar, atendendo à sua complexidade e características específicas. Por conflito, entendemos (11) a existência de diferentes percepções, face à mesma situação, apresentadas e sentidas pelos intervenientes na situação como mutuamente incompatíveis e inconciliáveis.

Considerando o conflito como algo necessário à mudança ou pelo menos inevitável ao relacionamento humano (12), que surge, mais cedo ou mais tarde, em qualquer relação, independentemente do grau de proximidade ou de intimidade, o mesmo ocorre com diferenças na intensidade e forma como cada sujeito sente e reage à sua gestão e resolução. Atendendo à atualização da conceitualização do conflito, como inevitável ou mesmo necessário (13), importa ao gestor hospitalar proceder a uma verificação sobre qual o seu 
mindset, ou seja, qual a configuração da sua mente, relativamente ao surgimento dos conflitos e resultados que pode trazer para a estrutura organizacional.

Ao gestor da saúde passa a ser exigida capacidade profissional e técnica para manter um nível adequado do conflito, que não cause improdutividade ou influência negativa na gestão de tempo, assim como recebe o especial dever de identificar e evitar situações de espiral destrutivo que, se irreversível, pode causar situações de stress e desgastes, originando faltas ao trabalho ou até doenças graves. Importa a esse gestor, que pretende atuar dentro dos atuais modelos de mercado, tomar consciência das diferentes possibilidades de reação, desenvolvendo competências para decidir qual o melhor comportamento e atitude face ao contexto, analisando a situação concreta, características dos intervenientes e interesses da organização.

Para aprofundar este tema, escolhemos o TKI, desenvolvido por Kenneth W. Thomas e Ralph H. Kilmann (14), com origem do começo da década de 1970 e baseado em aprimoramentos teóricos sobre o modelo de estilos de conflitos gerenciais proposto por Robert R. Blake e Jane Mouton, na década de 1960. O instrumento TKI permite, a partir de um questionário (14), identificar as tendências comportamentais de um indivíduo ao lidar com conflitos interpessoais, descrevendo as suas tendências comportamentais dentro dos cinco estilos de comportamentos possíveis na gestão e resolução de conflitos.

Consideramos o TKI como uma das principais ferramentas de mensuração de comportamento nas situações de conflitos, porque são analisadas duas dimensões, ou eixos, na identificação dos estilos de comportamentos perante as situações concretas: o grau de assertividade, quando o sujeito pretende satisfazer os seus próprios interesses e preocupações; e o grau de cooperatividade, quando o sujeito pretende satisfazer os interesses e preocupações do outro. Com o cruzamento das duas dimensões, é possível identificar e localizar cinco estilos de comportamentos e qual a preferência do sujeito para a situação ou temática em concreto: competir; evitar; acomodar; conciliar; colaborar.

Analisando as atitudes ou comportamentos apresentados, podemos referir o seguinte: competir descreve o sujeito que persegue suas próprias preocupações às custas da outra pessoa, ou seja, é assertivo não cooperativo, pois defender uma posição que acredita estar correta ou simplesmente tentar vencer; acomodar é ser pouco assertivo e muito cooperativo, o oposto de competir, significando negligenciar suas próprias preocupações para satisfazer as preocupações da outra pessoa, ou seja, sacrifica seus interesses pessoais para satisfazer 
os do outro; evitar é fugir do problema ou simplesmente adiar tomar posição, implicando em não fazer algo, ou seja, não ser assertivo nem cooperativo; comprometimento, mais conhecido como conciliar interesses, tem como principal objetivo encontrar uma solução rápida e aceitável que satisfaça parcialmente ambos, sendo que em algumas situações pode significar dividir a diferença entre as duas posições, corresponde a um comportamento moderadamente assertivo e moderadamente cooperativo; e colaborar, no sentido de envolver um trabalho conjunto dos intervenientes para encontrar ou construir uma solução que satisfaça totalmente os interesses e preocupações de todos, sendo totalmente assertivo e totalmente cooperativo (14).

Sobre os cinco comportamentos possíveis, importa reforçar que não existe qualquer hierarquia ou ordem de preferência, ou mesmo uma situação padrão a alcançar. Todos os sujeitos conhecem e usam os cinco comportamentos de acordo com as circunstâncias e objetivos pretendidos alcançar. O instrumento TKI (15) serve de catalisador para abrir discussões sobre questões difíceis e facilitar o aprendizado sobre como os modos de gestão e resolução de conflitos afetam a dinâmica pessoal, de grupo e organizacional.

É possível verificar a predominância comportamental para cada situação, conseguindo analisar qual o processo mais adequado para o objetivo pretendido. De forma a ficar mais claro, vamos apresentar alguns exemplos respeitando a confidencialidade. Se tivermos uma situação de relação continuada quando, por questões de hierarquia, o subordinado é forçado a aceitar uma decisão imposta numa situação de conflito, a relação passa a ser de autoritarismo e não de autoridade, criando ao longo do tempo desinteresse e falta de motivação. De igual modo, se o subordinado sempre cede algo com o qual não concorda numa situação de conflito em benefício de uma boa relação com o gestor, como por exemplo fazer o trabalho de outro colega pouco diligente, vai aumentando as expetativas de receber algo em troca, como uma promoção, que se não vier a ocorrer criará frustração. Já o comportamento de colaboração corresponde ao maior desafio para o gestor, em especial para o gestor na saúde, atendendo às características das relações continuadas com interesses subjetivos, alguns relacionados a status e egos, e interesses objetivos da organização.

O necessário desenvolvimento de competências técnicas para identificar interesses, necessidades e desejos subjacentes potencializa, por um lado, a possibilidade de explorar um desacordo para se aprender com as ideias uns dos outros e, por outro, encontrar e 
construir soluções criativas que atendam aos interesses e necessidades subjetivas e objetivas de todos os envolvidos.

Importa conhecer e reconhecer os diferentes estilos utilizados pelos diferentes intervenientes; saber identificar os elementos do conflito na construção prévia do seu mapa, com os elementos estáticos e dinâmicos; bem como gerir e resolver efetivamente a situação com os comportamentos e processos mais adequados aos objetivos pretendidos.

O gestor consensual, que trabalha com autonomia e utiliza um modelo restaurativo de situações e relacionamentos, precisa estar preparado para o exercício de uma função de prevenção dos conflitos, antecipando-se aos mesmos, nomeadamente através do desenho de sistemas de resolução de disputas (DSD, dispute system design) e outros processos que otimizam a sua resolução de forma adequada, promovendo um bom clima organizacional, com boa reputação e imagem, para além da satisfação dos clientes internos e externos.

Por DSD, ou desenho de sistema de conflitos, em português, entenda-se a criação e construção de sistemas de negociação personalizados, em especial para empresas e organizações, com o objetivo de otimizar a resolução de conflitos, podendo esta ser realizada online, com redução de custos, tempo, tranquilidade, acessibilidade e sem barreiras territoriais (15).

\section{Diagnóstico de conflitos na gestão da saúde}

Antes de proceder à identificação da situação ou prescrever uma eventual solução, através de um determinado processo ou método, importa fazer um diagnóstico da instituição ou organização, começando exatamente por conversar com as pessoas com atuação ou interesse para escutar qual o modelo que entendem existir na organização. Em seguida, procede-se ao levantamento do organograma da instituição para verificação das congruências e incongruências entre o que existe formalmente e o que se faz na prática, em especial sobre os níveis de hierarquia, competência, legitimidade e responsabilidade na tomada de decisão.

Essa análise prévia possibilita verificar se o organograma é ou não conhecido formalmente pela estrutura institucional, bem como se existe conhecimento sobre competência, responsabilidade e rede formal de decisão em caso de conflito, em especial qual a relação de autoridade e legitimidade para resolver divergências ou situações de risco e urgência. 
A clareza sobre o organograma, responsabilidades e fluxo do processo decisório da organização facilita a percepção dos colaboradores e gestores sobre fluxos decisórios relativos às diferentes situações, bem como, em especial, às ações que se interligam (16).

É comum em estruturas da saúde, em especial instituições hospitalares com organização informal, existirem situações de boicotes a rotinas estabelecidas, designadamente por parte do corpo clínico e médico, quando não concordam com elas. Tal ação origina desentendimento com o restante da equipe, gerando conflitos entre subculturas da organização, por meio de processos de pressão, conseguindo que a rotina seja revista, ao invés da utilização de espaços que favoreçam e instiguem o diálogo e a comunicação. Esse tipo de comportamento, denominado de competitivo (ou aversão do profissional com relação a regras procedimentais), é justificado por alguns pelo fato de não terem vínculo empregatício, o que pode prejudicar os interesses da organização da qual fazem parte.

Sabemos que, na área da saúde (clínica, médica e hospitalar), a hierarquia costuma ser apontada como sendo um fator que dificulta a agilidade dos processos no cotidiano. Isso acontece, em especial, nas organizações ou instituições de maior porte, cujo maior desafio não é o desconhecimento do organograma, mas sim a cultura organizacional (17), principalmente se a instituição já foi receptiva a contatos diretos que ignoravam hierarquia. Tal comportamento é justificada em situação de emergência, quando se ultrapassa processos, estruturas e fluxos decisórios, porém, constituindo-se seguramente um fator gerador de conflito e absoluto mal-estar organizacional.

Entender a dinâmica dos conflitos e diagnosticar, nomeadamente, se a autonomia dos médicos escapa ao controle da área administrativa e aos padrões de gestão, relacionandose apenas com mecanismos de pressão na estrutura administrativa, exige por parte dos administradores, diretores e gestores, além de conhecimento técnico sobre conflito, elevadas competências de comunicação e negociação.

\section{Comunicação}

Apesar de entendermos a comunicação como um tema óbvio, já que desde tenra idade nos comunicamos, importa desenvolver o quanto complexa essa temática pode ser, em especial quando nos referimos à comunicação institucional ou organizacional na área da saúde. Aqui, as competências de gestão e liderança também devem ser orientadas para a implementação e desenvolvimento de processos de diálogo, com a especificidade do 
necessário e efetivo entendimento da complexidade das relações e relacionamentos, bem como da sua especial continuidade.

Conforme as novas competências da gestão na saúde, em especial ao nível estratégico e de gestão desenvolvido pela presidência, administração, coordenação e supervisão, além de um conhecimento profundo sobre a complexidade e diversidade de elementos do conflito no ambiente institucional e organizacional, os profissionais precisam entender tecnicamente sobre as formas de relacionamento e canais de comunicação, notadamente entre supervisores e subordinados, mas também entre as diferentes áreas, desde o comercial à clínica médica, passando pelo operacional e atendimento, até à governança, entre outras.

Desenvolver o tema comunicação implica entender a sua dinâmica, contexto e complexidade (19), sendo a maior dificuldade da comunicação organizacional no plano cultural, e não no formal, o que dificulta a execução e aprimoramento de processos, gerando conflitos entre os diferentes níveis hierárquicos que diariamente precisam lidar com as dificuldades inerentes à ausência de diálogo, comunicação e troca de diferentes opiniões. Favorecer e instigar canais específicos e apropriados para o diálogo é de suma importância, quer seja por meio de um canal interno aberto e confidencial, como um disque denúncia ou um serviço de apoio ao cliente interno (colaborador e prestador de serviço), quer por meio de uma ouvidoria ou central de atendimento ao cliente interno e externo.

Abordar o tema comunicação significa apresentação e desenvolvimento de ideias, escuta, devolução do entendimento do que se escutou e confirmação de ter sido entendido (7). Sucede que é exatamente esse o caminho que cada vez menos é percorrido pelos sujeitos, que tendem a fazer deduções do que foi dito, ao invés de verificarem e confirmarem o que pretenderam transmitir ao outro.

Nesse ponto, precisamos refletir sobre a crescente tendência de falar para o outro, em vez de falar com o outro, assim como de escutar para responder, ao invés de escutar para entender, gerando ruídos de comunicação e situações desconfortáveis que possibilitam o desenvolvimento de conflitos evitáveis (19).

Sobre ruídos na comunicação que ocorrem diariamente dentro de uma estrutura com diversas culturas, é importante entender que ocorre pela falta de feedback. Emissor, codificação, canal ou meio, receptor, descodificação, resposta e contexto, correspondem aos 
principais elementos do processo de comunicação, bem como seus axiomas, em especial que é impossível não se comunicar (20).

A conversação entre sujeitos é algo dinâmico e muitas vezes realizada de forma inconsciente ou intuitiva, mas o gestor precisa cuidar da comunicação e usá-la com conhecimento técnico e profissional.

Saber se comunicar vai muito para além de saber falar e ouvir. Impõe o desenvolvimento de competências sobre comunicação (20), em especial comunicação não violenta, com uma escuta proativa, bem como efetiva gestão de emoções e sentimentos, que por regra afetam o racional nos momentos de tensão.

O gestor precisa aceitar o desafio de passar a efetivamente desenvolver uma comunicação onde cada interveniente fala com o outro e escuta para entender. Utilizar uma linguagem clara e um meio adequado são algumas das principais preocupações que a instituição e o gestor precisam ter atenção.

De igual modo, o gestor deve refletir sobre como nos comunicamos em situações de conflito, como reagimos perante conversas difíceis (21) - seja pelas características das pessoas (pessoas difíceis) ou pelas circunstâncias da situação (situações difíceis) - e o que podemos mudar para otimizar esses impasses e dificuldades (22).

Segundo Marshall Rosemberg, é importante termos e aplicarmos um procedimento próprio de comunicação, através de quatro passos, para alcançar uma comunicação efetiva (19). Propõe o autor (19), depois de escutar atentamente, começar por devolver de forma objetiva a situação que entendemos e estamos a vivenciar, prosseguindo com a verbalização do sentimento que nos provoca, para, em seguida, esclarecer ao outro sobre a nossa necessidade, terminando com um pedido legítimo. Nesse sentido, o processo de comunicação não violenta ocorre em quatro passos durante a mesma fala: descrição do modo como observo a situação e ações do outro (sem julgamento); partilha do sentimento individual, usando a linguagem do eu sobre a situação; manifestação das necessidades individuais com base nos valores e desejos gerados; e realização do pedido claros e específicos, com critérios objetivos (19).

No caso específico das relações e relacionamentos na área da saúde, em especial da gestão clínica, médica e hospitalar (11), implica para o gestor o desenvolvimento de competências específicas necessárias para comunicar com pessoas que têm uma diversidade de valores, e consequentemente de diálogos e linguagens. Assim, de acordo com os 
intervenientes em questão, será possível ocorrer situações em que será necessário gerir diferentes usos de linguagem: umas com valores éticos e extremamente técnica (médicos, enfermeiros e staff técnico); outras com valores emocionais (famílias, pacientes e acompanhantes); e outras com valores financeiros (empresas, operadoras e seguradoras), podendo inclusive se misturarem (23).

Resulta claro que elementos subjetivos do conflito e questões de continuidade da relação estão presentes em todas as situações e sujeitos mencionados, sendo, por regra, mais adequado resolvê-los de forma saudável e construtiva, por meio de processos consensuais que imperem a autonomia da vontade e decisão informada, como é o processo de mediação.

Comunicar assertivamente e sem violência implica treino e prática, sendo necessário o gestor da saúde conseguir ser capaz de construir, de forma efetiva e consistente, culturas empresariais modernas, onde diálogo construtivo e respeito ocupam um campo fértil e abundante, com consequências diretas na redução do índice de conflitos, mantendo o gestor com foco no desenvolvimento da sua área de negócio sem distrações.

\section{Negociação}

Perante situações de negociação conflituosa, mas com interesses divergentes, a tendência é ocorrer um escalar destrutivo da relação, contaminando ambiente e demais sujeitos. Diferentemente, quando existem interesses distintos, mas objetivos comuns, usando da negociação, com atitudes e comportamentos de cooperação (14), as divergências podem se transformar em desafios saudáveis ao ambiente, bem como potencializar proximidade das relações entre os intervenientes e demais sujeitos.

De forma complementar ao objetivo do presente trabalho, importa aqui tratar o tema da negociação (24), sendo necessário afirmar que, tal como no aprofundamento sobre a comunicação, o que aparentemente parece ser óbvio é efetivamente complexo, por suas potencialidades e dimensões serem imensas.

Durante a gestão de conflitos vão ocorrer situações em que o gestor da saúde precisa ter um pulso assertivo e tomar decisões, assumindo responsabilidades e consequências do uso desse poder que the foi conferido. No entanto, existem outras situações de conflito em que trabalhar as divergências por meio do uso de processos cujos interessados elaboram favorece ambientes com relações continuadas. 
Desenvolvido após a Segunda Guerra Mundial, pelo projeto de negociação da Universidade de Harvard, a negociação por interesses corresponde a um método negocial, com procedimentos pensados para o negociador convencer o outro de forma consensual e construir acordos sem necessitar de fazer concessões (24). O procedimento sobre como chegar ao sim encontra-se dividido em quatro passos: separar pessoas dos problemas; concentrar-se nos interesses e desvalorizar as posições; criar opções de ganhos mútuos; e por fim, insistir na utilização de critérios objetivos com padrões independentes.

O principal objetivo desse tipo de negociação (24) é, além de atingir um resultado objetivo com rapidez, construir um acordo que satisfaça os intervenientes através da distribuição de ganhos mútuos.

Por ser muito diferente da forma com que somos educados, é importante fazer uma interiorização dos conceitos sobre a construção de soluções de ganhos mútuos (24), para em seguida se conscientizar de que a maioria das pessoas ainda não conhece essa possibilidade e insiste no velho modelo de uma negociação na qual um ganha e o outro perde ou os dois perdem.

É preciso aprofundar alguns conceitos sobre diferentes modelos de negociação e quais as possíveis abordagem, assim como os resultados prováveis de serem alcançados (25), começando por verificar a forma de pensar durante o processo e mesa de negociação. Posteriormente, é necessário identificar se o negociador tem foco em ganhar do outro, sempre querendo levar vantagem, ou se, diferentemente, o foco é ganhar com o outro, de forma recíproca, alcançando e construindo soluções impossíveis de atingir se agisse sozinho ou se escolhesse outros meios para resolver a situação, caso chamasse um terceiro com poder de decisão para impor uma solução.

Uma das situações mais correntes de provocar ou potencializar conflitos diz respeito ao descumprimento de combinados assumidos numa negociação. Pessoas que dizem sim para acabar com a situação, mas na verdade fazem o contrário. Essa situação ocorre muitas vezes pela sensação de desconforto e incômodo que dizer não lhes causa, estejam ou não no exercício de funções de gestão. Ultrapassar a frágil capacidade de dizer não, impõe o desenvolvimento de competências sobre como dizer um não positivo (26), ou seja, como ter uma atuação assertiva na sua gestão e liderança.

Saber dizer não de forma assertiva implica conhecer e estabelecer uma estratégia de atuação, por meio da qual, após uma escuta ativa, se demonstra entendimento e 
compreensão sobre os interesses do outro, dizendo sim; em seguida, apresenta os fundamentos e motivações da sua posição e interesses de forma interessada, verbalizando o não; e finalizamos com a manifestação de disponibilidade para atender os interesses do outro desde que os nossos também o sejam, propondo a construção de uma solução que atenda a todos, concluindo de forma positiva com uma saída honrosa para os demais intervenientes (26).

Compete ao gestor hospitalar desenvolver competências técnicas para negociar com maior eficiência e eficácia, mas também importa que tenha conhecimento da existência de processos de mediação e conciliação, em caso de impasse, entre outros métodos consensuais de resolução de conflitos.

É preciso, de forma sumária, distinguir o processo de mediação e conciliação, tendo por base o disposto no regime legal brasileiro, em especial no Código de Processo Civil (27) e na Lei no 13.140, de 26 de junho de 2015, chamada de Lei de Mediação (28).

Estabelece o artigo 165ำ do CPC que a diferença entre os dois processos se encontra na circunstância da mediação ser adequada, preferencialmente, nos casos em que houver vínculo anterior entre as partes, tendo por objetivo auxiliar os interessados a compreender as questões e os interesses em conflito, de modo que eles possam, pelo restabelecimento da comunicação, identificar soluções consensuais que gerem benefícios mútuos por si mesmos. Diferentemente, a conciliação é um processo legalmente considerado mais adequado, preferencialmente nos casos em que não houver vínculo anterior entre as partes, podendo um terceiro sugerir soluções para o litígio, tendo como objetivo o acordo, mas sem qualquer tipo de constrangimento ou intimidação para que as partes conciliem. Ainda nos termos da lei, em especial o artigo $1^{\circ}$ da $\mathrm{n}^{\circ}$ 13.140, mediação é considerada uma atividade técnica, exercida por terceiro imparcial, sem poder decisório, que, escolhido ou aceito pelas partes, as auxilia e estimula a identificar ou desenvolver soluções consensuais para a controvérsia. Diferenças e semelhanças serão aprofundadas em momento posterior.

\section{Introdução aos principais métodos de resolução de conflitos}

O conflito, além de inevitável aos relacionamentos humanos, corresponde a uma diferente percepção da mesma situação, tida como mutuamente incompatível e inconciliável para os intervenientes. Por meio do desenvolvimento das aludidas teorias sobre o conflito, 
veio a ser descrito por uns como oportunidade, e por outros como algo necessário ao desenvolvimento da humanidade.

Atendendo à mudança de valores sociais, relacionais e institucionais, bem como ao modo como as relações se dão na atualidade, as sociedades modernas vêm resgatando o efetivo exercício do princípio da autonomia da vontade privada e da decisão informada nas últimas décadas.

Apesar de não ser uma matéria nova, ainda se verifica a falta de informação sobre as diferentes possibilidades e escolhas de processos e técnicas para uma gestão e resolução de conflitos com eficiência e eficácia.

Sem nos aprofundarmos muito, impõe-se afirmar a existência de três grandes grupos de processos de resolução de conflitos: heterocompositivos, híbridos e autocompositivos.

A aludida divisão foi por nós realizada atendendo, em especial, ao critério legal de autonomia da vontade privada. Assim, quanto menor for a autonomia da vontade mais próximo estaremos da decisão do terceiro. Inversamente, quanto maior for a aludida autonomia mais próximo estaremos da construção da solução de forma livre.

Classificamos como processos híbridos quando, apesar de um terceiro decidir definitivamente, é preciso de uma cláusula compromissória estabelecida previamente no contrato para iniciar o processo, ou de um compromisso arbitral acordado durante o conflito. A conciliação, apesar de preservar a autonomia dos intervenientes, admite como possível a circunstância do conciliador poder sugerir formas de resolver a situação, podendo o aludido princípio ficar condicionado.

Conhecedores das dificuldades de certas negociações, principalmente aquelas onde ocorrem impasses, entendidos pelos intervenientes como divergências absolutamente incompatíveis e inconciliáveis, ou onde os intervenientes atingiram um nível de ruptura que Ihes impede a escuta, em especial quando ocorre perda de confiança ou insegurança, impõese o recurso de um terceiro.

A questão está exatamente na escolha desse terceiro, pois podemos escolher um terceiro com poder de decisão, ou um terceiro sem poder de decisão, mas com domínio de processos que restabelecem a comunicação e a confiança, possibilitando construir soluções consensuais e duradouras, com foco nas relações continuadas.

A tendência de escolha de um terceiro com poder de decisão, advém do modelo educacional, familiar, no trabalho ou mesmo na sociedade, e pela absoluta falta de 
consciência e treino sobre o poder que cada sujeito tem de resolver definitivamente a situação por si mesmo, conseguindo ultrapassar problemas, impasses e dificuldades mediante processos de cooperação e consenso.

Assim, podemos chamar um terceiro, alguém da nossa rede, de acordo com determinado critério pessoal ou de identidade, a quem delegamos competência para analisar e decidir a situação por nós. Podemos indicar um terceiro atendendo a questões técnicas ou formais, que nos irá substituir e ser parcial, a exemplo de um profissional da advocacia. Ou ainda, um terceiro profissional que irá atuar de forma imparcial, de acordo com determinado processo, princípios, regras e procedimentos, como o mediador que auxiliará a comunicação e facilitará a construção de soluções que atendam a todos.

\section{Processo de mediação de conflitos na saúde}

Por mediação, entendemos o processo vocacionado para trabalhar conflitos entre pessoas com interesse em manter, melhorar, não prejudicar ou iniciar relacionamentos ou relações, quando a negociação não deu certo, independentemente do grau de proximidade e/ou intimidade, com a intervenção de um terceiro especializado, sem poder de decisão ou ingerência, denominado de mediador. Diferentemente, o processo de conciliação aplica-se à resolução de situações entre pessoas que tiveram uma relação pontual, ocasional ou esporádica, tendo como objetivo descobrir os interesses mensuráveis e a identificação das questões em divergência, facilitado por um terceiro que, sem poder de decisão, tem a faculdade de poder sugerir um acordo para colocar um fim rápido à situação (29).

No âmbito empresarial, a mediação é hoje utilizada para trabalhar conflitos entre organizações, clientes, fornecedores e colaboradores, com possibilidade de aplicação em três momentos distintos: (i) na prevenção ou minimização dos efeitos e consequências da disputa; (ii) na gestão mais profunda e produtiva dos fatores relacionados à disputa; ou (iii) na obtenção de uma solução mais eficiente e eficaz da disputa (30).

Das experiências vivenciadas pela autora durante a sua carreira, com diversos casos de mediação empresarial, envolvendo alto, médio e baixo cargo de gestão, na área clínica, médica e hospitalar, entre diferentes subculturas e, em especial, entre médicos e administradores hospitalares, é possível referir que, na relação entre médicos e demais grupos ainda prevalecem práticas competitivas e autoritárias que dificultam ou impedem tomada de decisão conjunta pelo grupo de trabalho, com modelos de gestão verticais ou 
matriciais. Assim como ainda encontramos, com frequência, a percepção de superioridade da classe médica em relação aos demais técnicos e profissionais. De igual forma, é notória a presença de conflitos latentes, ocultos ou reprimidos, em resultado da divergência entre quem exerce o poder e quem está sujeito a ele.

Situações de desautorização médica sobre decisões dos administradores e diretores, além de descredibilizar, provocam desgaste emocional e relacional, bem como comprometem a produtividade das equipes e aumentam a insegurança a processos de legitimidade e responsabilidade na tomada de decisão.

O processo de mediação na área da saúde, e em especial na gestão médica, clínica e hospitalar, é o mais adequado para as situações elencadas, podendo funcionar de modo interno, com a criação de equipes de profissionais da própria instituição que, capacitadas para o exercício dessa função de mediador, a exercem em horários pré-estabelecidos e num local criado para tal. A mediação também é possível funcionar de modo externo, com a solicitação de intervenção de mediadores profissionais, capacitados e certificados, em especial com atuação reconhecida no mercado privado.

De uma forma ou de outra, o gestor estará impedido de exercer a função de mediador no sentido técnico do termo, atendendo à necessária intervenção parcial da sua atuação, mas será fundamental, e em especial dadas as particularidades das múltiplas partes envolvidas e que se inter-relacionam (pacientes, família, médicos, enfermeiros, assistentes, técnicos, companhias seguradoras, planos de saúde, entre outros), possuir competências sobre o triângulo do conhecimento na sua função de gestor: conflito, comunicação e negociação, além de conhecimentos sobre as potencialidades de recorrer e propor a mediação como processo adequado para determinados conflitos (9).

Reforçando, a mediação é um processo vocacionado para trabalhar conflitos onde exista interesse de manter, melhorar, não prejudicar ou iniciar relacionamentos ou relações, em que a negociação direta não deu certo, independentemente do grau de proximidade e/ou intimidade (29).

Enquanto processo de prevenção, gestão e resolução de conflitos, em especial na área da saúde, e em concreto na realidade clínica, médica e hospitalar, a mediação de conflitos corresponde a uma proposta para trabalhar divergências entre pessoas que mantêm uma relação continuada na busca de seus interesses, objetivos e subjetivos, e na identificação de suas questões. Facilitados por um terceiro, intervém buscando o 
entendimento das diferenças, o restabelecimento da comunicação e estimula uma composição satisfatória para ambas.

Com características específicas, o processo de mediação rege-se por princípios processuais determinados e estabelecidos nos diferentes ordenamentos jurídicos do Brasil, dos quais destacamos como universais, a confidencialidade, informalidade, flexibilidade e oralidade. Também é importante a voluntariedade e o controle sobre o resultado por parte dos intervenientes, atendendo à autonomia da vontade. Além da independência e imparcialidade do mediador para buscar o consenso dos mediados, tratando-os com isonomia e igualdade, é importante a atuação de boa-fé dos mediados nos termos do CPC e da mencionada Lei de Mediação.

\section{Mediador de conflitos}

O mediador de conflitos é um profissional técnico, especializado na prevenção, gestão e resolução de conflitos, sem poder decisório, com formação específica no processo de mediação. Foi escolhido ou aceito pelos intervenientes por meio de procedimentos próprios e os auxilia a entenderem o conflito; estimula o diálogo dos intervenientes; e os incita a tratar suas diferenças de forma consensual, construtiva e colaborativa, para, em conjunto, após identificar interesses e necessidades, construírem possibilidades de solução de ganhos mútuos na resolução da situação (29). Seja interno ou externo à instituição, o mediador de conflitos terá uma atuação independente e imparcial, além da obrigação de atuar com a confidencialidade do processo.

Durante a sua intervenção, o mediador atua facilitando a comunicação, provocando o diálogo, incitando o tratamento das diferenças de forma construtiva, colaborativa e consensual e estimulando a criatividade para a construção de soluções de ganhos mútuos com base em critérios objetivos. Inclui-se nas funções desse profissional, auxiliar os intervenientes a entenderem o conflito e as divergências, estimular a identificação dos diferentes interesses e necessidades dos envolvidos, seja pessoa ou organização representada, e instigar que os intervenientes à construção de possibilidades de soluções consensuais. 


\section{Conclusão}

Podemos concluir que tal como outras profissões e realidades, também na área da saúde, e em especial na médica, clínica e hospitalar, é impossível insistir na manutenção das mesmas estruturas organizacionais, com atuação paralela entre o sistema administrativo e assistencial, porquanto a gestão e controle financeiro de uma organização depende da gestão racional de recursos no atendimento e satisfação dos interesses do cliente, cada vez mais exigente e com maior poder de escolha, fruto do aumento da concorrência.

O maior desafio para a administração e gestão na saúde é quebrar paradigmas sobre a tradicional forma de gerir esse tipo de instituições. Designadamente, conseguir implementar, na prática, modelos de governança e gerenciais que promovam canais de comunicação e diálogo efetivo e que estimulem a construção de consenso nas decisões e uma maior homogeneidade na distribuição do poder de decisão.

No mesmo sentido, é fundamental criar modelos e diferentes formas de gestão que tenham por base o compartilhamento da tomada de decisão e divisão de responsabilidades. Importa registar que as diversas resistências que ainda se encontram ocorrem, em geral, por falta de conhecimento das diferentes formas de liderança e resolução de diferenças, especialmente os modelos de negociação consensual com ganhos mútuos, e sobre as vantagens do processo de mediação de conflitos.

O gestor e administrador hospitalar não é e nem pode atuar como mediador técnico, mas é fundamental o seu conhecimento sobre o processo de mediação, assim como sobre procedimentos, ferramentas e técnicas utilizadas. Além disso, é de grande valia o desenvolvimento de competências nos temas de conflito, comunicação e negociação.

A utilização do processo de mediação na prevenção, gestão e resolução de conflitos na área da saúde e, em especial, nas áreas da competência de gestão clínica, médica e hospitalar, traz inúmeros benefícios organizacionais. Por meio dos seus princípios e procedimentos próprios, o processo de mediação permite salvaguardar a imagem dos intervenientes e a gestão sobre o tempo dispendido no processo (confidencialidade, simplicidade e flexibilidade), assim como o controle do resultado e autonomia da decisão.

A imparcialidade do mediador e o procedimento em si permitem preservar e acolher aspectos emocionais envolvidos em situações de relacionamento continuado, restabelecendo a necessária segurança e confiança para, por meio de uma visão prospetiva, construir de forma criativa soluções ajustadas aos interesses e necessidades de todos os 
intervenientes e que restaurem os relacionamentos, independentemente do grau de proximidade ou de intimidade .Em síntese: utilizar o processo de mediação na prevenção, gestão e resolução de conflitos na saúde permite uma previsão e controle sobre o tempo, desgaste e investimento financeiro, além do efetivo controle sobre a decisão final pelos intervenientes, que podem estabelecer acordos parciais ou totais, provisórios ou definitivos.

Temos plena convicção e segurança ao afirmar que as vantagens competitivas dos modelos de gestão hospitalar da atualidade caracterizam-se pela tomada de consciência de que os diferentes papeis, em especial, os médicos, técnicos e administradores hospitalares, ao decidirem e atuarem colaborativamente, inclusive usando o processo de mediação para ultrapassar impasses de forma consensual, conseguirão um efetivo aumento de produtividade, o aperfeiçoamento da qualidade dos serviços prestados e maior qualidade relacional dos diferentes intervenientes, operacionalizando vantagens competitivas da organização no mercado e uma real humanização das interrelações e do direito médico.

\section{Referências}

1. Weber M. Economía Y Sociedad - esbozo de sociologia compreensiva. Fondo de Cultura Económica; 1992.

2. Gonçalves E. Administração de recursos humanos nas instituições de saúde. São Paulo: Pioneira; 1987.

3. Hatch MJ. Organization Theory. New York: Oxford University Press Inc.; 1997.

4. Heloani R. Organização do trabalho e Administração: uma abordagem multidisciplinar. São Paulo: Cortez; 1994.

5. Heifetz RA. Leadership without easy answers. Cambridge: Harvard University Press; 1994.

6. Matos AJ. Gestão de custos hospitalares. São Paulo: STS; 2001.

7. Uribe RFJ. Análise estratégica em saúde e gestão pela escuta. Rio de Janeiro: Fiocruz; 2003.

8. Vendemiatti M, Siqueira ES, Filardi F, Binotto E, \& Simioni FJ. Conflito na gestão hospitalar: o papel da liderança. Ciência \& Saúde Coletiva. 2010; 15: 1301-1314.

9. I Semana Advogar na Mediação. O triângulo do conhecimento [Online]. Projeto Advogar na Mediação; 2020. 
10. Rossetti JP, Andrade A. Governança corporativa: fundamentos, desenvolvimento e tendências. 7ª̣ ed. São Paulo: Atlas; 2014.

11. Nascimento D. Mediação de Conflitos na Área da Saúde: experiência portuguesa e brasileira. Cadernos Ibero-americanos de Direito Sanitário. 2016; 5(3), 201-211.

12. Follett MP. Profeta do gerenciamento. Rio de Janeiro: Qualitymark; 1997.

13. Deutsch M. The Resolution of Conflicts. Yale University Press; 1973.

14. Kenneth WT, Kilman RH, Kilman Thomas. Conflict Mode Instrument [Online]. 1997. Disponível em: https://kilmanndiagnostics.com/overview-thomas-kilmann-conflict-modeinstrument-tki/

15. Faleck D. Manual de Design de Sistemas de Disputas. Lumen Juris; 2018.

16. Robbins SP, Judge TA, Sobral F. Comportamento organizacional: teoria e prática no contexto brasileiro. 9ª ed. São Paulo: Pearson Education do Brasil; 2002.

17. Motta, F. C. P. Transformação organizacional: a teoria e a prática de inovar. Rio de Janeiro: Qualitymark; 1997.

18. Bohm D. Diálogo: Comunicação e Redes de Convivência. Palas Athena; 2005

19. Rosenberg M. Comunicação Não-Violenta. Ed. Ágora; 2006.

20. Watzlawick P, Beavin JH. Pragmática da Comunicação Humana. Ed. Cultrix; 1967.

21. Patton B, Heen S, Stone D. Conversa difíceis: como argumentar sobre questões importantes. Rio de Janeiro: Elsevier; 2011.

22. Ury W. Supere o Não: negociando com pessoas difíceis. São Paulo: Best Seller; 2000.

23. Dolan SL. Coaching por valores. Madrid: LID Editorial Empresarial; 2012.

24. Fisher R. Ury W, Patton B. Como chegar ao sim: negociação de acordos sem concessões. Rio de Janeiro: Imago Editora; 2005.

25. Nascimento DMM. A mediação empresarial na Era do CPC/2015. In: Perruci FF, Ribeiro Maia FF, Leroy GC [Orgs]. Impactos do Novo CPC no Direito Empresarial. Belo Horizonte: Editora D’Plácido; 2017.

26. Ury W. O poder do não positivo: como dizer não e ainda chegar ao sim. Rio de Janeiro: Elsevier; 2007.

27. Brasil. Código de Processo Civil. Lei no 13.105, de 16 de março de 2015. Disponível em: http://www.planalto.gov.br/ccivil_03/_ato2015-2018/2015/lei/l13105.htm 
Brasil. Lei no 13.140, de 26 de junho de 2015. Disponível em:

http://www.planalto.gov.br/ccivil_03/_ato2015-2018/2015/lei//13140.htm

29. Nascimento DMM. Julgados de paz e conciliação técnica: sua importância no paradigma da Justiça Restaurativa. Disponível em:

http://repositorio.ulusiada.pt/bitstream/11067/716/1/md_dulce_nascimento_dissertacao.pdf. [Acesso em 4 fev 2020]

30. Nascimento D, Renno L. As vantagens da escolha pela Mediação Empresarial. In: Sztajn R, Salles MP de A, Teixeira T. Direito empresarial: estudos em homenagem ao professor Haroldo Malheiros Duclerc Verçosa. São Paulo: IASP; 2015

Nascimento DMM. Mediação de conflitos na gestão da saúde (médica, clínica e hospitalar): humanização do direito médico. Cadernos Ibero-Americanos de Direito Sanitário. 2020 jan./mar.; 9(1): 170-195.

http://dx.doi.org/10.17566/ciads.v9i1.605 